\title{
ENGAGEMENT MARKERS IN THE FEYNMAN LECTURES ON PHYSICS: APPLYING HYLAND'S INTERACTION FRAMEWORK TO SPOKEN ACADEMIC DISCOURSE
}

\author{
Natalia Kramar \\ Research and Educational Center of Foreign Languages, National Academy of Sciences of \\ Ukraine, Kyiv \\ kra_nat@ukr.net
}

\begin{abstract}
The paper presents an analysis of engagement markers in the Lectures on Physics by eminent scientist and Nobel prizewinner R. P. Feynman, based on K. Hyland's model of interaction in academic discourse as stance and engagement. The Lectures were taught at the California Institute of Technology during 1961-63 and, having been turned into a textbook, are widely used by Physics students even today. It is argued that the Lectures owe their lasting popularity not only to the simplicity of explication, but also to Feynman's masterful use of interaction devices, particularly reader pronouns, directives, questions, references to sharedness and personal asides. Reader pronouns are analysed in comparison with the MICASE-based reference corpus, with the most common youand we-clusters being identified. It is established that reader pronouns, directives and questions in the Feynman's Lectures on Physics mostly perform the functions of anticipating possible objections, eliciting prior knowledge, focusing students' attention, stimulating their thought and creativity, while references to sharedness and personal asides serve to strengthen the lecturer's communality with the audience, particularly through the use of humour. We draw the conclusion that Hyland's taxonomy of engagement markers can be applied to spoken academic discourse in its entirety and can be particularly useful for the description of interactive styles of acknowledged scientists, supplementing depersonaliased corpus research in search for best practices in pedagogy.
\end{abstract}

Keywords: lectures; R.P. Feynman; engagement; academic discourse; reader pronouns.

\section{Introduction}

The last two decades have witnessed a burst of interest to authorial voice in academic discourse, with a particular focus on interpersonality. Once viewed as impersonal and faceless, academic communication is today universally recognised as a persuasive endeavour, where the author's self-representation and interaction with the readers can be a critical factor determining the reception of his/her ideas in the disciplinary community. Among spoken genres of Academic English, the greatest attention so far has been paid to lecture as the chief format of instruction in tertiary education (Bamford, 2005; Chang 2012). Though lectures tend to be monologic, they contain many instances of language targeted toward reducing the distance between the speaker and the audience. As noted by Chafe (1982), lectures are characterised by the so-called "experiential involvement": the speakers are required to communicate and demonstrate their own emotional participation, in contrast to writers, who are removed from their audience. Deroey \& Taverniers (2011) view interacting function as one of the six discourse functions of lectures, with its subfunctions being regulating interaction, involving the students and establishing a relationship with the students. Apart from creating the atmosphere that is beneficial to learning, interaction increases lecture comprehension, which is particularly important in light of the current internationalisation of education (Morell, 2004). The manifestations of interactivity in lectures that have been addressed by scholars include the use of personal pronouns (Fortanet, 2004; Morell, 2004; Okamura, 2009, Rounds, 1987, Yeo and Ting 2014), discourse markers (Eslami \& Eslami-Rasekh, 2007; Morell, 2004), questions (e.g., Bamford, 2005; Crawford Camiciottoli, 2008; Fortanet, 2004; Morell, 2004), and asides (Crawford Camiciottoli 2007; Fortanet 2004; Strodt-Lopez 1991). Many scholars remark that there is a global move toward more conversational and informal lecturing style (Morell, 2007; Chang, 2012), which adds urgency to the problem of interaction in lectures.

We are aware of the fact that, with corpus research being the predominant trend in EAP, the value of analysing single author's works seems not to be self-evident. However, we agree with Heller \& Morek (2015, p. 179) that it would benefit the field greatly to shift focus from systemic, generalised features of academic discourse to individual and situated language use. The present research is focused on the Feynman Lectures on Physics (henceforth FLP), an extraordinarily popular Physics textbook, based on the lectures R. P. Feynman presented to undergraduate students at Caltech in 1961-63. Richard Feynman was an acclaimed physicist and Nobel prizewinner, but he was also known for his many eccentricities, ranging from frequenting strip clubs to safecracking. Remaining the most comprehensive and widely-read physics course for decades, the FLP seems well worth research, which can hopefully bring forth insights on efficient use of interaction in the essentially monologic genre of a university lecture.

Kramar, N. (2019). Engagement markers in the Feynman lectures on physics: applying Hyland's interaction framework to spoken academic discourse. Advanced Education, 12, 127-133. DOI: 10.20535/2410-8286.144603 


\section{Methods}

Underlying our research is the concept of stance and engagement as two dimensions of interaction in academic writing, developed by Ken Hyland, a paramount figure in the EAP landscape (Hyland, 2005). In his framework, the stance is the attitudinal aspect related to the ways writers present their views, beliefs and judgments, whereas engagement is an alignment aspect related to the writer's strategies of recognising the presence of the readers and drawing them into dialogue. Engagement is subcategorised into reader pronouns, directives, questions, references to shared knowledge and personal asides. As Hyland observes, engagement is addressed in the literature significantly less often than stance (Hyland, 2011, p. 200).

For the purposes of our research, both quantitative and qualitative methods were used. The five categories of engagement markers were colour-coded in QDA Miner software (Provalis Research, 2011), with subsequent manual analysis. AntConc (Anthony, 2018) was utilised for the keyword, frequency and collocation analysis, whenever relevant (primarily, for reader pronouns). We also compiled a reference corpus of monologic MICASE lectures (102 766 tokens) to examine Feynman's engagement mode against the backdrop of modern lecture discourse. It should be noted that the FLP were eventually arranged in a textbook and underwent a great deal of editing to be adjusted for reading. Therefore, corpus tools are only used as a complementary method, which helps us to identify the features specific of Feynman, without any intention of profound comparative research.

\section{Results and Discussion}

\section{Reader Pronouns}

Reader pronouns are the most explicit marker of a lecturer's interaction with the audience. They include you and inclusive we, which serves "to draw the listener into the ongoing discourse and create intersubjectivity between speaker and audience" (Bamford, 2009, p. 205), unlike exclusive we, which refers to the writer/speaker only and thus emphasises the distance between the two parties. As noted by Hyland, you and your are quite rare to be found in academic writing (2005, p. 182), but in spoken discourse, you is used more extensively due to the actual presence of the audience.

Based on our analysis, R. P. Feynman uses the pronoun we in the FLP 8 times more often than you. Though we sometimes takes the exclusive value, referring either to the speaker himself or the scientific community he belongs to, inclusive use is largely predominant, making up more than $95 \%$ of all cases. Inclusive pronouns are widely believed to help scientists convey positive politeness and reinforce communality by acknowledging the audience as disciplinary equals (Harwood, 2005). Therefore, it is hardly surprising that, as reported by Rounds (1987), the most successful teaching assistants used we about three times more often than other personal pronouns. However, from the time of Round's report, the situation has changed towards increasing use of $I$ and you in academic lectures (Fortanet, 2004; Okamura, 2009; Yeo \& Ting, 2014; Lee \& Subtirelu, 2015). These findings led scholars to re-examine the value of we and you in constructing dialogism in academic discourse: thus, Yeo \& Ting (2014) claim that frequent use of you in university lecture introductions creates a personalised style that draws students into the lecture (2014, p. 35). It seems reasonable to assume that you and we can serve to both reduce and increase the distance between the speaker and the students, depending on the particular context and simultaneous non-verbal signals. To better understand the role of personal pronouns in the lecture discourse and to identify the interactive features that are specific to R. Feynman's lecturing style, we undertook an analysis of the most frequent you- and weclusters in the FLP in comparison with the respective clusters in highly monologic MICASE lectures from different fields.

Table 1 demonstrates top you-clusters in the FLP and the MICASE, with their frequencies per 10, 000 words. When used in the preceding position, you in the FLP is mostly collocated with can, which is also typical of the MICASE ( $2^{\text {nd }}$ position). In both corpora, you can frequently serves as a part of the combination you can see (23\% and $17 \%$ of the general use in the FLP and the MICASE, respectively). As noted by Fernández Polo in his study on conference presentations, this phrase mostly performs the function of creating a shared interpretation of presented data: the information that follows is positioned as the inferences that the audience have made on their own, based on the visual props $(2018$, p. 18). The second most common youcluster in the FLP is you will, which only ranks $13^{\text {th }}$ in the MICASE, according to AntConc cluster analysis. It is mostly featured in the phrases that aim at focusing the students' attention (you will * see -44 occurrences; you will * notice/note - 35 occurrences) and at eliciting prior knowledge (you will * remember - 24). The latter use has no parallel in the reference corpus at all. The cluster you see is common to both corpora (ranking $6^{\text {th }}$ in the MICASE) and signals the lecturers' reference to visual data and trying to mould its shared interpretation, quite similarly to you can see. Finally, the fifth frequent cluster with you in the 
preceding position in the FLP is you may, being far not that popular in the MICASE ( $31^{\text {st }}$ position). This cluster is mostly featured in phrases like you may say, you may wonder/be wondering, you may think/be thinking: thus, its high frequency is telltale of Feynman's desire to anticipate the potential objections that the audience may have by seeming to "read their minds". Unparalleled in the reference corpus, the anticipatory function of you is one of the salient characteristics of Feynman's interactional lecturing style. The clusters you are and you get, featured in the MICASE column, are quite common in the FLP as well, occupying the $6^{\text {th }}$ and the $7^{\text {th }}$ positions, respectively. The cluster you know ranks so high in the MICASE only due to the use of unedited transcripts in the corpus: it is mostly utilised as a filler phrase and it certainly cannot be that frequent in an edited text.

Regarding you-clusters with you in the post-position, if you, that you and when you are common to both corpora, while as you and show you are significantly more prevalent in the FLP. The cluster as you is primarily featured in phrases as you can see, as you will see, thus being another marker of Feynman's copious references to visual data. It also often appears in as you know (15 occurrences), which is used to activate prior knowledge of the students. The high frequency of show you is accounted for by demonstrative rather than merely explanatory nature of the FLP and the field of physics, in general.

Table 1. Top you-clusters in the FLP and the MICASE

You in the preceding position

\begin{tabular}{|l|l|}
\hline FLP & MICASE \\
\hline you can $(4,75)$ & you know $(35,4)$ \\
\hline you will $(\mathbf{3}, \mathbf{1 4})$ & you can $(18,7)$ \\
\hline you have $(1,53)$ & you are $(17,4)$ \\
\hline you see $(\mathbf{1}, \mathbf{4 0})$ & you have $(11,9)$ \\
\hline you may $(\mathbf{1}, \mathbf{3 1})$ & you get $(6,22)$ \\
\hline
\end{tabular}

You in the post-position

\begin{tabular}{|l|l|}
\hline FLP & MICASE \\
\hline if you $(4,8)$ & if you $(24,6)$ \\
\hline that you $(1,49)$ & and you $(12,6)$ \\
\hline as you $(\mathbf{1 , 2 2})$ & that you $(12,3)$ \\
\hline when you $(1,06)$ & so you $(7,00)$ \\
\hline show you $(\mathbf{0 , 6 0})$ & when you $(6,61)$ \\
\hline
\end{tabular}

The use of pronoun we in the FLP is mostly consistent with that in the MICASE, as can be seen from Table 2. The only outliers are the clusters we would and if we, which are interconnected as they introduce the main clause and the subordinate clause of conditional sentences. R. Feynman indeed tends to broadly use conditional clauses, oftentimes in series, when testing different kinds of assumptions in the process of explication. However, the cluster we would is not only used to introduce an apodosis: in $25 \%$ of cases, it is accompanied with the verb like and is used to present the next point to be discussed in the lecture. Contrariwise, the MICASE shows the frequent use of I'm going to or I'd like to for this purpose, but never we would like. R.P. Feynman also occasionally resorts to exclusive pronoun use in announcing his intentions (I want to, I would like to), but we-clusters we want (266 occurrences) and we would like (91 occurrences) are massively predominant. Therefore, Feynman tends to express his volition as though it is shared by the audience, thus fostering their greater involvement. Concerning the use of $I$, it appears in the FLP 176 times, as compared with 15, 724 occurrences of we. Meanwhile, in the MICASE the proportion of their use is nearly equal (834 and 837 occurrences, respectively). On the whole, R. Feynman comes across as a very selfwithdrawing lecturer: it is only very rarely that he voices his opinion explicitly ( $I$ think -3 occurrences, $I$ believe -2 occurrences), preferring to hide behind the authority of the expert community he belongs to (we think - 45 occurrences, we believe - 17 occurrences). In the MICASE, the lecturers are much more willing to express their stance directly, referring to themselves as the only agents. Certainly, this can be part of the global informalisation process that has taken place in scientific discourse since the time the Feynman Lectures came out.

Having compared the immediate context of we and you in the FLP, we can see that the functions specific to you are demonstration (you see, show you, as you + can see), anticipation (you may), while specific to we is outlining the course of the lecture (we will, we would + like). In the MICASE, we is likewise associated with outlining lectures (we will), but in general, the immediate context of the two pronouns is quite similar. 
Table 2. Top we-clusters in the FLP and the MICASE

$W e$ in the preceding position

\begin{tabular}{|l|l|}
\hline FLP & MICASE \\
\hline we have $(37,02)$ & we are $(16,92)$ \\
\hline we can $(27,66)$ & we have $(7,20)$ \\
\hline we will $(11,15)$ & we will $(6,13)$ \\
\hline we are $(10,15)$ & we have $(5,64)$ \\
\hline we would $(\mathbf{8 , 5 0}, \mathbf{5 0}$ & we can $(3,60)$ \\
\hline
\end{tabular}

$W e$ in the post-position

\begin{tabular}{|l|l|}
\hline FLP & MICASE \\
\hline if we (27, 62) & that we $(6,61)$ \\
\hline that we $(14,22)$ & and we $(6,52)$ \\
\hline when we $(8,22)$ & so we $(4,47)$ \\
\hline and we $(6,95)$ & what we $(3,99)$ \\
\hline so we $(6,94)$ & when we $(3,79)$ \\
\hline
\end{tabular}

\section{Directives}

Directives are engagement markers that request the readers/listeners to perform a certain action, whether it be cognitive, textual or physical (Hyland, 2005). They are mostly represented with imperatives, modals of obligation, and predicative adjectives dealing with importance or necessity (e.g. "It is essential to remember"). R. P. Feynman uses a broad range of imperatives in the FLP, most of which aim at stimulating the students' imagination and thinking process (suppose - 725 occurrences; imagine - 109 occurrences) and directing their attention to the issues he deems important (consider - 189 occurrences, see -149 occurrences, notice/note - 103 occurrences, look - 117 occurrences). All of these directives are also common in the MICASE lectures, except for consider, which was not found to occur in the reference corpus in the imperative function (nor in combination with modals of obligation). Almost half of the directives in the FLP are mitigated with the starter let us, which, according to Hyland, "has the effect of transforming an instruction into an invitation" (2008, p. 154). The imposing force of directives is also diminished with the use of the indicative mood in the utterances where the imperative mood might well be used (e.g. you will remember, you will notice, which have not been identified in the reference corpus), with the use of inclusive we as subject (e.g. we now wish to consider, we must remember), and with impersonal utterances (e.g. one must be careful). Strong forms of directives, such as you must, you have to, you should are relatively uncommon in the FLP (about 60 occurrences in total). Most notably, R.P. Feynman has a special form of giving directions, which is not featured in the reference corpus: we leave it for you ... to (alternatively - for the reader, to the student). This formula occurs in the FLP 18 times, e.g.

We leave it for you to find the conditions for which this is so. (Vol. II, Lecture 22)

Therefore we leave it to the student to work out the formula for the spherical mirror [...] (Vol. I, Lecture 27)

Thus, Feynman's way of instructing the students is marked with particular tentativeness and consideration for his audience, as he prefers mild and descriptive forms of directing whenever possible.

\section{Questions}

Questions are used in academic discourse to incite interest and encourage the reader/listener to explore a certain issue as an equal partner in the discussion (Hyland, 2005). A powerful device of stimulating human interaction, they have long been recognised as crucial in facilitating teaching and learning processes (Chang, 2012). They steer readers in a desired direction, while also being used as part of organisational and rhetorical strategies (Crawford Camiciottolli, 2008). In her seminal study, Thompson (1998) suggested a widely popular distinction between audience-oriented questions (where a response is plausible, though it may not be provided) and content-oriented questions (where no response is expected). As further elaborated by Crawford Camiciottolli (2008), audience-oriented questions can be targeted at eliciting response, requesting information and soliciting agreement, while content-oriented questions can be divided into those focusing information and stimulating thought (with the additional category of suggesting action, which is not always applicable). Due to the fact that the FLP underwent heavy editing prior to being published, the only audience-oriented questions left in the corpus are aimed at checking the students' comprehension ( Can you see...?, Do you see...?). Most of the content-oriented questions serve to focus information (being thus followed with an immediate answer), but Feynman also makes a broad use of questions that are stimulating thought with the purpose of encouraging reflection on the part of the audience, without providing explicit answers. Instead, they are followed by the author's suppositions (example 1), requests for the audience to suggest their own solution (example 2) or even with helpless statements nobody knows or we do not know (examples 3 and 4), e.g.:

1. Is it not possible that perhaps gravitation is due simply to the fact that we do not have the right coordinate system? After all, we can always get a force proportional to the mass if we imagine that a body is accelerating... (Vol. I, Lecture 12) 
2. Which argument is correct? Will the disc rotate or will it not? We will leave this question for you to think about. (Vol. II, Lecture 17)

3. The question is, of course, is it going to be possible to amalgamate everything, and merely discover that this world represents different aspects of one thing? Nobody knows. (Vol. I, Lecture 2)

4. Why does it keep on coasting? We do not know, but that is the way it is. (Vol. 1, Lecture 7)

Examples 3 and 4 illustrate Feynman's ubiquitous integrity underlying his teaching style and interaction with students: he does not position himself as an omniscient expert, but readily draws the attention of the audience to the gaps in available knowledge, so that they may contribute to their closing with time. Notably, the stimulating questions often come in series, having a strong emotional charge, e.g.:

What about still smaller times? Does "time" exist on a still smaller scale? Does it make any sense to speak of smaller times if we cannot measure - or perhaps even think sensibly about — something which happens in a shorter time? Perhaps not. (Vol. I, Lecture 5)

Such series of questions are mostly placed in lectures' introductory sections, where they clearly serve the purpose of motivating and intriguing the students. With his trademark striving for a unified picture of the world, Feynman virtually bombards his audience with an overwhelming amount of fundamental problems that the humankind has not been able to solve yet, thus allowing the students to see the global perspective behind the matter at hand.

\section{References to sharedness}

In Hyland's perspective (Hyland, 2005, p. 184), references to sharedness, or appeals to shared knowledge, are explicit markers where the audience are asked to recognise the proposed information as familiar, thus identifying with particular author's views. They are most often represented with the boosters of course, obviously, clearly and the like, which seemingly assign to the audience a participatory role in the discourse, while often being used to pose an author's personal beliefs as collective understanding or disciplinary norm. As to the modifier of course, in particular, K. Hyland notes that, along with being a marker of epistemic stance, it has the power to shift the focus away from the writer in shaping the role of the recipient (2001, p. 16). In the FLP, of course is one of the most common modifiers, which is generally used to refer to the disciplinary knowledge that the students are required to have, especially that related to the methods, procedures and limitations of physics. The frequency of of course in the FLP in more than 2 times higher than in the MICASE (10, 3 versus 4, 8 occurrences, calculated per 10, 000 words). It is often accompanied with the phrase we know, which serves to accentuate the engagement of the audience even more. All throughout the FLP, we can see Feynman's trying to underline the facts that the students already know as well as he does, thus granting the audience with the sense of parity and participation in the discourse.

However, references to shared knowledge can also be interpreted in a broader sense, encompassing all mentions of background knowledge that the author expects the audience to hold for their successful communication. The latter approach has been adopted by Fortanet et al. (2004), who have identified three common types of references, such as those to immediate context (circumstances of the speech event), discipline, and cultural background (location, age group, nation, and Western civilization). While the bulk of the references to shared knowledge in the FLP are closely related to the discipline, Feynman occasionally mentions the location where the lectures were delivered - the Caltech - in the context of scientific achievements associated with it. However, it is notable that Feynman tends to appeal to universal experiences shared by people, irrespective of their cultural background and age. One remarkable domain of reference is childhood experiences, e.g.

We can all remember, as children, playing in the bathtub or in mud puddles with the strange stuff. As we get older, we watch streams, waterfalls, and whirlpools, and we are fascinated by this substance which seems almost alive relative to solids. (Vol. II, Lecture 40)

Those who were entertained in childhood by the baking powder box which has on its label a picture of a baking powder box which has on its label a picture of a baking powder box which has ... may be interested in the following problem. (Vol. II, Lecture 6)

Using the references of this kind not only serves the purpose of presenting a comprehensible analogy for the physical phenomena being discussed but also helps the lecturer in breaking the ice and relieving tension by introducing the element of humour.

\section{Personal asides}

Personal asides are comments the author inserts in mid-flow of the argument: rather than providing useful factual or explicatory information, they serve to initiate a brief interpersonal dialogue and thus 
strengthen the author's relationship with the audience (Hyland, 2005, p. 183). Recognised as a salient constituent of any well-prepared lecture, asides serve to increase its comprehensiveness and cohesion, while also performing the interactive function (Strodt-Lopez, 1991; Fortanet-Gómez and Ruiz-Madrid, 2015). Referring to asides in lectures as "digressions", Fortanet-Gómez and Ruiz-Madrid (2015) have brought forth the following classification: context-based digressions (location context, lecture context, relation between subject matter in lectures and "real life" for presenter or audience), utterance-based digressions (clarifications), and addressing the audience directly. While the predominant type of asides in the FLP are clarifications (about $70 \%$ of all cases), personal evaluating comments (tying the lecture topics with the "real life") are also common, with addressing the audience directly being negligibly rare. Most strikingly, R. P. Feynman is not afraid of expressing explicit criticism, ranging from soft irony to outward deprecation. Thus, we find 9 instances of critical remarks targeted at philosophy, which Feynman despised throughout his life, as evident from his memoirs (Feynman, 1985), e.g.:

Philosophers, incidentally, say a great deal about what is absolutely necessary for science, and it is always, so far as one can see, rather naive, and probably wrong. (Vol. I, Lecture 2)

When this idea descended upon the world, it caused a great stir among philosophers, particularly the "cocktail-party philosophers," who say, "Oh, it is very simple: Einstein's theory says all is relative! (Vol. I, Lecture 16).

Such comments can be viewed in terms of deprecatory humour, which draws the line between in- and out-groups: by disparaging the members of an out-group (in this case, philosophers), the lecturer reinforces the in-group identity and nourishes their sense of superiority (Nesi, 2012). Though at other times Feynman also finds faults with physics, these remarks sound more like irony than deprecation, e.g.

Physicists always have a habit of taking the simplest example of any phenomenon and calling it "physics," leaving the more complicated examples to become the concern of other fields - say of applied mathematics, electrical engineering, chemistry, or crystallography. (Vol. II, Lecture 31)

\section{Conclusions}

We have analysed engagement markers in the lectures of acknowledged physicist Richard P. Feynman, using Ken Hyland's model of interaction in academic discourse as our theoretical framework. With regard to the most explicit engagement device - reader pronouns - we have found that inclusive we is used in the FLP 8 times more often than you, while in modern lectures you is much more favoured. Until recently, inclusive we was believed to strengthen communality in academic discourse, but nowadays scholars claim that you can serve lecturers better as it creates the atmosphere of personal communication. Nonetheless, the notable preponderance of inclusive $w e$ in one of the most successful lecture series of all times seems to give an additional score to this pronoun in its ongoing competition with you. As to other categories, anticipating students' thoughts, softening directives and using amplification in questions, combined with uncompromising honesty in recognising the limitations of science, are Feynman's core interactive strategies, being to a great extent responsible for the unceasing popularity of his Lectures on Physics.

To summarise, Hyland's model of engagement markers in academic discourse turns out to be fully applicable to the spoken genre of lecture, all the more so because references to sharedness and personal asides are more common in speech as compared to rather formalised medium of academic writing. The detailed taxonomy of these markers, however, is still a work in progress, with many areas being interpreted variously by researchers. Hopefully, EAP scholars will turn more attention to situated personal discourses of eminent scientists as they obviously feel more unrestricted in their academic communication than little known or aspiring researchers, whose works are used in modern corpus research.

\section{References:}

Anthony, L. (2017). AntConc (Version 3.5.7). Tokyo, Japan: Waseda University. Retrieved October 15,2017 from http://www.laurenceanthony.net/software

Bamford, J. (2005). Interactivity in academic lectures: The role of questions and answers. In J. Bamford \& M. Bondi (Eds.), Dialogue within discourse communities: Metadiscursive perspectives on academic genres (pp. 123-145). Tubingen, Germany: Max Niemeyer.

Bamford, J. (2009). Patterns of description in lectures in science and technology. In: S.Radighieri and P.Tucker (Eds.), Point of View: Description and Evaluation across Discourses (pp. 195-210). Rome: Officina Edizioni.

Chafe, W. (1982). Integration and Involvement in Speaking, Writing, and Oral Literature. In D.Tannen (Ed.),, Spoken and Written Language: Exploring Orality and Literacy (pp. 35-53). Norwood: Ablex.

Chang, Y. (2012). The use of questions by professors in lectures given in English: Influences of disciplinary cultures. English for Specific Purposes, 31(2), 103-116. DOI: https://doi.org/10.1016/j.esp.2011.08.002

Crawford Camiciottoli, B. (2007). The Language of Business Studies Lectures: A corpus-assisted analysis. Amsterdam Philadelphia: John Benjamins Publishing Company. 
Crawford Camiciottoli, B. (2008). Interaction in academic lectures vs. written text materials: the case of questions. Journal of Pragmatics, 40(7), 1216-1231. DOI: 10.1016/j.pragma.2007.08.007

Deroey, K., \& Taverniers, M. (2011). A corpus-based study of lecture functions. Moderna språk, 105(2), 1-22.

Eslami, Z. R., \& Eslami-Rasekh, A. (2007). Discourse markers in academic lectures. Asian EFL Journal, 9(1), 22-38.

Fernández Polo, F.J. (2018). Functions of "you" in conference presentations. English for Specific Purposes, 49 (14-25). https://doi.org/10.1016/j.esp.2017.10.001

Feynman, R. P. (1985). “Surely you're joking, Mr. Feynman!": Adventures of a Curious Character. New York: W. W. Norton \& Company.

Feynman, R.P. (2013). The Feynman Lectures on Physics. The California Institute of Technology. Retrieved September 20,2017 from http://www.feynmanlectures.caltech.edu/

Fortanet, I. (2004). The use of "we" in university lectures: reference and function. English for Specific Purposes, 23 (1), $45-66$. https://doi.org/10.1016/S0889-4906(03)00018-8

Fortanet, I. (2006). Interaction in Academic Spoken English: the Use of 'I' and 'you' in the MICASE. In: E. Arnó Maciá, A. Soler Cervera and C. Rueda Ramos (Eds.), Information Technology in Languages for Specific Purposes: Issues and Prospects (pp.117). Dordrecht, Netherlands: Kluwer Academic Publishers.

Fortanet, I., Palmer, J. \& Ruiz, Y. (2004). Interaction through shared knowledge in American, British and Spanish business lecture". Paper presented at the 2nd Symposium on Intercultural, Social and Cognitive Pragmatics, Sevilla, May 2004.

Fortanet-Gomez, I. \& Ruiz-Madrid, N. (2015). Multimodal humour in plenary lectures in English and in Spanish. In: B. CrawfordCamiciottoli and I. Fortanet-Gómez (Eds.), Multimodal Analysis in Academic Settings. From Research to Teaching (pp.39-60). New York: Routledge.

Harwood, N. (2005). 'We Do Not Seem to Have a Theory ... The Theory I Present Here Attempts to Fill This Gap': Inclusive and Exclusive Pronouns in Academic Writing. Applied Linguistics, 26 (3), 343-375. https://doi.org/10.1093/applin/ami012

Heller, V., \& Morek, M. (2015). Academic discourse as situated practice: An introduction. Linguistics and Education, 31, $174-186$. Retrieved September 20, 2017 from https://www.academia.edu/27442391

Hyland, K. (2001). Bringing in the reader: Addressee features in academic articles. Written Communication, 18(4), 549-574. https://doi.org/ 10.1177/0741088301018004005

Hyland, K. (2005). Stance and engagement: A model of interaction in academic discourse. Discourse Studies, 7(2), $173-192$. https://doi.org/10.1177/1461445605050365

Hyland, K. (2011). Disciplines and discourses: Social interactions in the construction of knowledge. In D. Starke-Meyerring, A. Paré, N. Artemeva, M. Horne, and L. Yousoubova (Eds.), Writing in the knowledge society (pp. 193-214). West Lafayette, IN: Parlor Press and The WAC Clearinghouse.

Lee, J. \& Subtirelu, N. (2015). Metadiscourse in the classroom: A comparative analysis of EAP lessons and university lectures. English for Specific Purposes, 37, 52-62. https://doi.org/10.1016/j.esp.2014.06.005

Morell, T. (2004). Interactive lecture discourse for university EFL students. English for Specific Purposes, $23(3), 325-338$. https://doi.org/10.1016/S0889-4906(03)00029-2

Morell, T. (2007). What enhances EFL students' participation in lecture discourse? Student, lecturer and discourse perspectives. Journal of English for Academic Purposes, 6(3), 222-237. https://doi.org/10.1016/j.jeap.2007.07.002

Nesi, H. (2012). Laughter in university lectures. Journal of English for Academic Purposes, 11(2), 79-89. https://doi.org/10.1016/j.jeap.2011.12.003

Okamura, A. (2009). Use of personal pronouns in two types of monologic academic speech. The Economic Journal of Takasaki City University of Economics, 52(1), 17-26. Retrieved January 9, 2017 from https://www.semanticscholar.org

Provalis Research (2011). QDA Miner Lite. Retrieved January 9, 2017 from https://provalisresearch.com/products/qualitative-dataanalysis-software/freeware/

Rounds, P. (1987). Characterizing successful classroom discourse for NNS teaching assistant training. TESOL Quarterly, 21 (4), 643-671. https://doi.org/10.2307/3586987

Strodt-Lopez, B. (1991). Tying it all in: Asides in university lectures. Applied Linguistics, 12 (2), $117-140$. https://doi.org/10.1093/applin/12.2.117

Thompson, S. (1998). Why ask questions in a monologue? Language choice at work in scientific and linguistic talk. In: S. Hunston (Ed.), Language at Work. Clevedon, UK: Multilingual Matters.

Walsh, P. (2004). A complex interplay of choices: first and second person pronouns in university lectures. In: J.Bamford and L. Anderson (Eds.), Evaluation in Oral and Written Academic Discourse (pp. 32-52). Rome: Officina Edizioni.

Yeo, J. Y., \& Ting, S. H. (2014). Personal pronouns for student engagement in arts and science lecture introductions. English for Specific Purposes, 34, 26-37. https://doi.org/10.1016/j.esp.2013.11.001 